\title{
Study of Serum Resistin Levels in Patients with Chronic Hepatitis C Viral Infection
}

\author{
Dawlat El-Miligy' ${ }^{1}$ Zohdy M. Mohammed², Mohamed M. Atta ${ }^{3}$, Thanaa H. Belal ${ }^{2}$ \\ and Yehia Z. Mahran ${ }^{1}$
}

${ }^{1}$ Biochemistry Department, Faculty of Medicine, October 6 University

${ }^{2}$ Biochemistry and Tropical Medicine ${ }^{3}$, Departments Faculty of Medicine, BenhaUniversity.

Received: 04-12-2013

Accepted: 10-01-2014

Published:01-03-2014

*Corresponding author: E. mail: dawlatmiligy@ yahoo.com

\begin{abstract}
Resistin is an adipokine mainly expressed in adipose tissue and was shown to be involved in hepatic glucose and lipid metabolism and appears to play a pivotal role in hepatic insulin resistance. It has been documented that serum resistin may be implicated in the progression of chronic liver diseases towards cirrhosis. This study was conducted to evaluate serum resistin level in patients with chronic HCV infection and to evaluate its effect on the clinical picture and progression of the disease. To fulfill this aim, 36 patients with a chronic HCV infection were classified into two groups. Group 1: Included 18 cases of chronic HCV infection without evidence of cirrhosis (compensated) and Group 2: Consisting of 18 cases of chronic HCV infection with evidence of cirrhosis (decompensated). As well as 16 normal subjects were enrolled as a control group (Group 3). Patients were further classified according to Child-Pugh classification that depends on the degree of deterioration of liver functions into three groups: Child A: 15 patients, Child B: 8 patients and Child C: 13 patients. All members of the study were subjected to thorough history taking, full clinical examination, abdominal ultrasound and laboratory investigations including CBC, ALT, AST, total and direct bilirubin, serum albumin, blood urea and serum creatinine. HCV virus antibody was detected by ELISA as well as estimation of serum resistin. The results of the study showed elevated serum resistin in both groups of chronic HCV as compared to the controls. The level of serum resistin was significantly higher in patients with $\mathrm{HCV}$ complicated with cirrhosis than compensated group. This finding may be of value in predicting the progress of $\mathrm{HCV}$ into cirrhosis. Moreover, according to the Child-Pugh classification serum resistin level was significantly higher in the diseased groups compared to control group. However, there was no significant difference between the various groups when compared to each other. Correlation study showed only positive correlation between ascites and serum resistin level. From the previous finding it could be concluded that monitoring serum resistin could be of value in the follow up of patients for prediction early detection of hepatic decomposition. However, its use for grading of liver dysfunction is not yet justified.
\end{abstract}

Key Words: Resistin, hepatic insulin resistance, HCV and CBC, ALT and AST.

\section{Introduction}

Hepatitis $\mathrm{C}$ virus $(\mathrm{HCV})$ is a major health problem worldwide. It has been estimated that globally over 170 million people are infected with chronic HCV infection and about 20-25\% of them are at risk of developing cirrhosis or even end stage liver failure(1). In Egypt, the problem is even more evident. HCV infection is the most important cause of liver disease according to Habib et al., (2) as the prevalence of antibodies to $\mathrm{HCV}$ is estimated to be 10 folds greater than Europe and the USA(3). Although in its natural history, chronic HCV infection is a slowly progressive disease. It has been estimated that $\mathrm{HCV}$ is the leading cause 
of cirrhosis and hepatocellular carcinoma (HCC) in this country (4). Adipose tissue, previously thought of as a passive storage site for excess energy, is now recognized as a hormonally active system producing numerous molecules known as adipokines, which exert local, central and peripheral actions. During the last decade, interest has turned to the study of this group of molecules and their role in chronic liver diseases (5). Resistin is one such adipokine, it is formed of a $10 \mathrm{kDa}$ protein composed of 94 amino acids. It was cloned in 2001 and is thought to be mainly expressed in adipose tissue. Resistin was shown to be involved in hepatic glucose and lipid metabolism and appears to play a pivotal role in hepatic insulin resistance (6). There have been a number of studies observing serum resistin levels in chronic liver diseases but they have mostly dealt with patients suffering from non-alcoholic fatty liver disease (NAFLD). In patients with NAFLD, abnormalities in the various adipokines (Resistin and leptin in particular) have been documented and possibly implicated in the progression of this disease towards cirrhosis (7). The aim of the present study is to investigate serum resistin level in cases of chronic hepatitis $\mathrm{C}$ in different stages of liver disease as well as its possible role in predicting the progression to cirrhosis.

\section{Subjects and Methods}

Thirty six patients with a chronic HCV infection were collected from the department of Tropical Medicine, Benha University as well 16 normal controls were included in the study. They were divided into three groups.

\section{Group 1:}

(control group) It consists of 8 males and 8 females their mean age \pm SD ranged $48.5 \pm 13.5$ years old.

\section{Group 2}

This group includes 18 patients with chronic HCV infection with no clinical evidence of

liver cirrhosis (compensated group). It consists of 14 males and 4 females their mean age \pm SD ranged $56.5 \pm 10.8$ years old.

\section{Group 3}

This group includes of 18 patients with a chronic $\mathrm{HCV}$ infection and a clinical or laboratory picture suggestive of liver cirrhosis (decompensated group). It consists of 15 males and 3 females their mean age \pm SD ranged $50.7 \pm 9.5$ years old

\section{Exclusion criteria for patient groups:}

1-Patients with mixed infection with both HBV and $\mathrm{HCV}$.

2- Patients with hepatic encephalopathy.

Exclusion criteria for control group:

1- A positive history for any liver disease.

2- Any person with positive for any Hepatotropic virus markers.

Patients were further subdivided into three groups according to the severity of chronic liver disease depending on Pugh's 1973 modifications of Child's grading of disease severity in chronic liver disease (Howdle 2000) as follows(8):

Child A: 15 patients non of these patient has ascites. Mean \pm SD of serum albumin was $3.4 \pm$ $0.3 \mathrm{gm} / \mathrm{dl}$, bilirubin was $1.1 \pm 0.2 \mathrm{mg} / \mathrm{dl}$ and INR was $1.4 \pm 0.2$ Child B: 8 patients 5 patients have ascites. Mean \pm SD of serum albumin was $3.0 \pm$ $0.4 \mathrm{gm} / \mathrm{dl}$, bilirubin was $2.7 \pm 1.1$ and INR was $1.5 \pm 2$ Child C: 13 patients All patients of this group have ascites. Mean \pm SD of serum albumin was $2.4 \pm 0.3 \mathrm{gm} / \mathrm{dl}$, bilirubin was $3.6 \pm 2.5$ and INR was $1.4 \pm 0.3$. All patients were subjected to the full clinical history, general and local examination for any manifestations of chronic liver diseases, abdominal ultrasound examination. The following laboratory investigations which performed to each subject:

-Serum albumin, Serum bilirubin, Prothrombin time, Urea and Creatinine levels by (Auto-analyzer - Synchron-CX9)

-HBV-Ab, HCV-Ab and serum resistin levels(9) by ELISA technique

\section{Sample preparation:}

$10 \mathrm{ml}$ blood was drawn from the anticubital vein. 8 $\mathrm{ml}$ were added in a plain test tube and $2 \mathrm{ml}$ in citrate for prothrombin assay. Blood was left to coagulate for 10 minutes then centrifuged for 10 minutes to separate serum.

Serum was stored at $-20 \mathrm{c}$ till time of assay.

\section{Calculation of results}

The mean absorbance for each set of duplicate standards, controls and samples were calculated and standard curve was plotted using Sigma plot software.

Data management and analysis: data was tabulated and introduced into a PC using SPSS 15.0.1) Pvalue: $<0.05$ is significant.

Tables $2 \& 3$ show serum and liver LDH activity, TBARS and Pr-SHs the concentrations of control and experimental groups of rats. Paracetamol (1 $\mathrm{g} / \mathrm{kg}$.), orally given to rats markedly increased serum and hepatic LDH activities. Also, the levels of serum and hepatic TBARS in paracetamol injected rats were significantly higher than control 
rats, whereas paracetamol injected rats-treated with the Sonchus oleraceus L. extract (ethanolic or aqueous) restored the altered values to the near normalcy. The decreased concentration of serum and hepatic Pr-SHs was observed in paracetamol injected rats. Administration of Sonchus oleraceus $L$. extract (ethanolic or aqueous) tends to bring the Pr-SHs level to near normal. Furthermore, vitamin $\mathrm{C}$ a proven liver protecting agent, also significantly inhibited the lipid peroxidetion of liver.

Tables $4 \& 5$ show the concentrations of blood and liver reduced glutathione (GSH), activities of superoxide dismutase (SOD) and glutathione peroxidase (GPx) of control and experimental groups of rats. The decreased concentration of blood and hepatic GSH was observed in paracetamol control rats. Administration of Sonchus oleraceus $L$. extract (ethanolic or aqueous) tends to bring the GSH level to near normal. The activities of SOD and GPx in liver were significantly lower in paracetamol injected rats compared to paracetamol injected rats-treated with Sonchus oleraceus $L$. extract (ethanolic or aqueous). Vitamin $\mathrm{C}$, on the other hand, also exhibited a significant hepatoprotective effect on the enzymes tested.

Histopathology of the liver: Histopathological examination of the liver sections from normal rats showed normal parenchymal architecture; no significant lesions were observed (Fig. 1A). In the rats treated with paracetamol alone, cloudy swelling, fatty degeneration, hepatocellular necrosis, heavy haemorrhage and irregular appearance due to cell death were seen (Fig. 1B). The above changes were reduced in the liver of rats treated with Sonchus oleraceus L. (ethanolic and aqueous $(150 \mathrm{mg} / \mathrm{kg})+$ paracetamol together (Fig. $1 C \& D)$. The histological pattern was almost normal in rats treated with vitamin $\mathrm{C}+$ paracetamol (Fig. 1E).

Table 1: Laboratory Data of Patients and controls

\begin{tabular}{|c|c|c|c|c|c|}
\hline $\begin{array}{c}\text { Biochemical } \\
\text { parametes }\end{array}$ & $\begin{array}{c}\text { Control group } \\
n=16\end{array}$ & $\begin{array}{c}\text { HCV without } \\
\text { cirrhosis } \\
n=18\end{array}$ & $\begin{array}{c}\text { HCV with } \\
\text { cirrhosis } \\
n=18\end{array}$ & P1 & $\mathbf{P 2}$ \\
\hline Albumin (gm/dl) & $4.1 \pm 0.4$ & $3.3 \pm 0.4$ & $2.5+0.3$ & $<0.0001$ & $<0.0001$ \\
\hline Bilirubin (mg/dl) & $0.8 \pm 0.2$ & $1.5 \pm 1.0$ & $3.2+2.3$ & $<0.0001$ & $<0.0001$ \\
\hline Urea (mg/dl) & $28.4 \pm 4.6$ & $16.7 \pm 10.6$ & $26.4+19.1$ & $<0.05$ & $<0.05$ \\
\hline Creatinine (mg/dl) & $1.1 \pm 0.1$ & $1.0 \pm 0.3$ & $1.2+0.6$ & N.S & N.S \\
\hline INR & $1.0 \pm 0.1$ & $1.4 \pm 0.2$ & $1.4 \pm 0.2$ & $<0.0001$ & N.S \\
\hline
\end{tabular}

P1: HCV compared to control

P2: HCVcompensated compared to HCV without cirrhosis

Table 2: Serum Resistin Among Chronic HCV Patients with and without cirrhosis Vs. controls

\begin{tabular}{|c|c|c|c|c|c|}
\hline & $\begin{array}{c}\text { Control } \\
\text { groupn=16 }\end{array}$ & $\begin{array}{c}\text { HCV without } \\
\text { cirrhosisn=18 }\end{array}$ & $\begin{array}{c}\text { HCV with } \\
\text { cirrhosis n=18 }\end{array}$ & P1 & P2 \\
\hline $\begin{array}{c}\text { Serum Resistin } \\
\text { ug/dl }\end{array}$ & $2.9+1.9$ & $7.9+2.0$ & $9.6+1.8$ & $<0.0001$ & $<0.0001$ \\
\hline
\end{tabular}

P1: compared to control

P2: HCVcompensated compared to HCV without cirrhosis 
Table 3: Serum Resistin Among Chronic HCV Patients According to Child Classification Vs. controls

\begin{tabular}{|c|c|c|c|c|c|c|c|}
\hline & $\begin{array}{c}\text { Control } \\
\mathbf{n}=16\end{array}$ & $\begin{array}{c}\text { Child A } \\
\mathbf{N}=15\end{array}$ & $\begin{array}{c}\text { Child B } \\
\mathbf{N}=8\end{array}$ & $\begin{array}{c}\text { Child C } \\
\mathbf{N}=13\end{array}$ & P1 & P2 & P3 \\
\hline $\begin{array}{c}\text { Serum Resistin } \\
\text { ug/dl }\end{array}$ & $\mathbf{2 . 9} \pm \mathbf{1 . 9}$ & $\mathbf{8 . 2} \pm \mathbf{2 . 0}$ & $\mathbf{9 . 1 + 2 . 2}$ & $\mathbf{9 . 3 + 2 . 0}$ & $<\mathbf{0 . 0 0 1}$ & N.S & N.S \\
\hline
\end{tabular}

P1: compared to control

P2: compared to Child A

P3: compared to Child B

\section{Discussion}

Resistin is an adipokine that has been implicated in many biological actions including liver fibrogenesis. Many reports demonstrated the presence of high resistin level in cirrhotic patients $(5,10)$. The study of serum resistin levels in HCV patients with and without liver cirrhosis was the main objective of this work. In this aspect, one of our first aims was to compare serum resistin levels in groups of chronic HCV with and without cirrhosis versus control group. Also, to investigate the relation between serum resistin and the degree of deterioration of liver function in hepatic patients classified according to the Child classification. The mean resistin levels were found to be significantly higher in patients with $\mathrm{HCV}$ when compared to control group. Also, it was significantly higher in uncompensated group compared to compensated group. The evaluation of serum resistin levels in the various stages of chronic HCV infections classified by the ChildPugh scoring system showed significantly higher level in patients of the three groups (Child A, B and $\mathrm{C}$ )compared to control group. However, no significant difference was observed when the 3 groups (Child A, B and C) were compared to each other.

An important similar study in this aspect is that of Bahr et al. (11), who measured serum resistin levels in cases of liver cirrhosis classified according to the Child-Pugh grading system. One further point in this study that deserves mentioning is that no statistically significant difference were detected in mean serum resistin between Child A and Child B groups, a result similar to that obtained in our study. Their results differ from our study in that the serum level of resistin in the Child $\mathrm{C}$ group were significantly elevated as compared to the other two groups
(Child A and B), a result found to be not significant in our work. An explanation for this was their comment that the serum resistin level in their study was affected not only by the severity of the disease but also by the underlying etiology. An example of this is that patients with alcoholic and biliary liver disease had similar resistin levels in Child C groups. However, the results of other etiologies (eg chronic viral hepatitis) are quite different in Child group C. Another explanation is that the Child classification depends on the degree of deterioration of liver cell function while resistin is not secreted by liver cells but it is secreted by the inflammatory cells in addition to adipocytes. It seems logical that their level is correlated with the degree of recruitment of inflammatory cells in the liver which is not related to the Child classification. Earlier animal experimentation on rodents proved that resistin was formed almost exclusively in the adipose tissue. Later on it was found that in humans the contribution of adipocytes to form resistin might be minor and monocytes/macrophages are the main contributors. They postulated that since $10 \%$ of the total liver mass is formed of Kupffer cells (resident macrophages), the significant increase of resistin in cirrhotic patients might be a response to an inflammatory stimulus, probably TNF-alpha. Whatever the reasons are, our results agreed with the work of Bahr et al., (11) in showing a highly significant increase in mean serum resistin levels in cirrhotic patients (as a group) when compared to control group(11). Another study which dealt with resistin levels and patients with cirrhosis was that of Kakizaki et al., (10). In this study, a group of patients with liver cirrhosis were compared to a control group of healthy people. The results also confirmed our study in showing a statistically 
significant elevation in mean serum resistin level in the patients as compared to the controls. The last study to be observed was that of El-Raziky et al., (5) who examined serum resistin levels in a group of children with a subgroup of cirrhotic cases (This study is included here because it originates in Egypt and that 17 out 29 patients had an $\mathrm{HCV}$ infection). Cirrhotic group showed a higher mean serum resistin level as compared to the controls a significant result as well. To summarize the results of the last three reported studies, all had statistically significant higher levels of serum resistin in the cirrhotic group as compared to the controls, which agree with our observed results. The study of Pagano et al., in 2011(12) concerning serum resistin levels in NAFLD deserves a special note for a variety of reasons, the most important of which is the estimation of resistin by a quantitative PCR technique (in addition to also measuring resistin levels in adipose tissue by PCR). The most important finding was that serum resistin level was significantly higher in NAFLD patients as compared to the controls. This significant relationship is similar to our result showing a high resistin level in $\mathrm{HCV}$ patients against controls although our patients had a higher mean resistin level. A very interesting observation in this study by Pagano et al., (12) was the fact that the serum resistin level correlated well with the nonalcoholic steatohepatitis (NASH) score but not with the steatosis. In other words, high resistin levels were found when there was an element of liver inflammation as opposed to a pure fatty liver. The study of Murad et al., in 2010(6) also deals with resistin levels in NAFLD but in this case resistin was measured using a sandwitch ELISA technique. The results also show a higher serum resistin level in patients with NAFLD as compared to the control. They also reported much higher resistin levels in patients with moderate to severe disease as opposed to the early stages. These two studies agree with our results in that patients with chronic liver disease (with an inflammatory component) have higher resistin levels than controls. The study of Murad et al., (6) also examined the idea that resistin may cause benign liver condition (Steatosis) to turn into an inflammatory steatohepatitis. Their explanation for this is that resistin may amplify selected proinflammatory mediators (IL-6 anf TNF alpha in particular) leading to liver damage. A study focusing on serum resistin in cases of chronic viral hepatic disease is that of Wong et al., (7). This group of scientists studied a large series of patients suffering from a chronic HBV infection and estimated the various levels of adipokines in them. The adipokines studied were serum adiponectin, leptin and resistin. HBV viral load in this study showed a positive correlation with serum adiponectin but not with serum resistin when studied as a sole factor. These results seem to contradict values found in our study. The main point in the conflict between these results and the present work (in our opinion) comes from the difference in the viral etiology. Although many researchers group chronic viral hepatic diseases together, yet they are not so. In HCV infections, viral factors play a less important role in the progression to cirrhosis with host factors (eg duration of infection) being significant elements. The progression to severe liver disease and cirrhosis takes 20-30 years to develop (13). The study of Mazur et al.,(1) concerned with the estimation of serum resistin levels in patients with chronic HCV infections who measured serum resistin levels in a group of 48 patients with a chronic HCV infection. They found that serum resistin level did not differ significantly between $\mathrm{HCV}$ cases and controls. Their final comment was in contrast to other investigators, they did not find significant differences between cases and controls and they recommend that further studies should be conducted on both serum and intra-hepatic resistin. On comparing the level of serum resistin between patients with $\mathrm{HCV}$ and those complicated with cirrhosis, a significantly higher value was noticed in the second group. This finding may be of value in predicting the progress of $\mathrm{HCV}$ into cirrhosis. From the previous findings it could concluded that determination serum resistin level could be of value in follow up of patients for prediction or early detection of decompensation. However, its use in accurate grading of stages of liver dysfunction is not yet justified.

\section{References}

1. Mazur W, Kulka $M$ and Benlowski $M$. Resistin, leptin and ghrelin serum levels among the patients with chronic hepatitis C. Experimental and clinical Hepatology 2010, 6 (4-3), 17-24.

2. Habib M, Mohamed MK and Abdel-Aziz F. Hepatitis $C$ virus infection in a community in the Nile Delta; risk factors for seropositivity. Hepatology, 2001; 33(1): 248-53.

Alter MJ, Kurszon-Moran D and Nainan OV. The prevalence of hepatitis $\mathrm{C}$ virus in the united states, 1988 through 1994 N. Engl.J. Med, 1999; 341(8):556-57. 
3. Abdel-Aziz F, Habib M and Mohamed M (2000): Hepatitis C virus (HCV) infection in a community in the Nile Delta: population description and HCV prevalence. Hepatology, 2000; 32: 111-15.

4. El-Raziky, M.S, Yousef, H, Salama, H.M, El Hawary, M, Salama, K and Abd El Moniem. Adipokines in Chronic Liver Diseases; Role in Pediatric Patients. Research Journal of Medicine and Medical Sciences, 2009; 4(2): 428-434.

5. Murad A, MD Hassan H, MD Husein H MD and Ayad A, MD. Serum resistin levels in nonalcoholic fatty liver disease and their relationship to severity of liver disease. JEMDSA 2010; 15 Number 1.

6. Wong $\mathrm{V}$, Wong $\mathrm{G}$, Yu J. Interaction of Adipokines and Hepatitis B Virus on Histological Liver Injury in the Chinese. Am J Gastroenterol 2010; 105:132-138.

7. Howdle PD. Comprehensive Clinical Hepatology. Harcourt Publishers Limited 2000.

8. Sheng CH, DI J, Jin Y, Zhang YC, Wu M, Sun $\mathrm{Y}$ et al..Resistin is expressed in human hepatocytes and induces insulin resistance. Endocrine 2008; 33:135-143.

9. Kakizaki S, Sohara $\mathrm{N}$ and Yamazaki Y.Elevated plasma resistin concentrations in patients with liver cirrhosis.J gastroentrology \& Hepatology vol 23, 1, 73-77

10. Bahr M, Ockenga J, Böker K, Manns M and Tietge U. Elevated resistin levels in cirrhosis are associated with the proinflammatory state and altered hepatic glucose metabolism but not with insulin resistance. Am J Physiol Endocrinol Metab. 2006 Aug; 291(2):E199-206.

11. Pagano C, Soardo G, Pilon C, Milocco C, Basan L, Milan G, Donnini D, Faggian D, Mussap M, Plebani M, Avellini C, Federspil G, Sechi L and Vettor R. Increased Serum Resistin in Nonalcoholic Fatty Liver Disease Is Related to Liver Disease Severity and Not to Insulin Resistance. The Journal of Clinical Endocrinology \& Metabolism 2006, 91; 10811086

12. Talley NJ (2008): Gastroentrology and Hepatology: A clinical handbook 2008 Elsevier Australia. 